\title{
Adverse Effects of Tobacco on Pregnancy Outcome
}

\author{
ME Rahman
}

\section{Introduction}

Tobacco, Nicotianatabacam of solanacae family, was originally cultivated in North America, thousands of years ago and smoked by indigenous Americans at least 2000 years ago, spreaded throughout the world after the arrival of the European settlers. ${ }^{1}$ Tobacco is being used in various forms, predominantly as smoking and smokeless tobacco (ST). About one third of the adults in the world including increasing number of women $(250$ million) daily smokes (22\% in developed world \& $9 \%$ of women in developing world. ${ }^{2}$ In Bangladesh smoking prevalence is $45 \%$ among men and $1.5 \%$ among women where $26 \%$ of men and $28 \%$ of women use smokeless tobacco in chewing form..$^{3,4}$ Smoking is an established cause of adverse pregnancy outcome. Smoking is associated with higher rates of abortion, ectopic pregnancy, stillbirth, placenta previa, abruptio placentae, premature rupture of the membranes, preterm birth, intrauterine growth retardation and sudden infant death syndrome (SIDS). ${ }^{5,6}$

Smoking during pregnancy can lead to a plethora of health risks to both the mother and the fetus. Women who smoke during pregnancy are about twice as likely to experience the following additional pregnancy complications ${ }^{7}$ : premature rupture of membranes, placental abruption, placenta previa, premature birth, sudden infant death syndrome (SIDS); birth defects associated with smoking during Pregnancy are heart defects (odds ratio 1.09), musculoskeletal defect (odds ratio 1.16), clubfoot (odds ratio 1.28), eye defects (odds ratio 1.25), orofacial defects (odds ratio 1.28), anal atresia (odds ratio 1.20), hernia (odds ratio 1.40). Smoking can also cause other birth defects e.g. reduced birth circumference, altered brainstem development, altered lung structure, and cerebral palsy. ${ }^{8}$

Tobacco contains thousands of compounds that may have adverse effects on the human body. Nicotine is the major compounds of significance. Nicotine is metabolized to many different compounds, the most notable being cotinine. Nicotine and its active metabolite cotinine increases maternal blood pressure and heart rate. Fetal heart rate is also increased. There is concomitant reduction in the blood flow of uterine artery and umbilical artery. ${ }^{9}$, 10 Nicotine also impairs placental transfer of amino acids and affects fetal brain development which may cause fetal hypoxia and growth retardation. ${ }^{11,12}$ ST users are exposed to higher level of nicotine than smokers. The systemic absorption of nicotine per dose is greater with use of chewing tobacco (average $4.5 \mathrm{mg}$ from average dose of 7.9 gchewed over 30 minutes) compared with that from smoking cigarettes (average $1 \mathrm{mg}$ per cigarette). ${ }^{13}$ Nicotine of ST may cause same adverse pregnancy outcome as smoking.

Tobacco is an important public health issue and a number of studies had been carried out focusing adverse effects of tobacco on pregnancy outcome. The most recognized effect of maternal smoking is the increased risk LBW baby. In addition to preterm delivery tobacco, both in smoking and smokeless form, is associated with intrauterine growth retardation (IUGR). Deshmukh JS et al 14 studied the prevalence of LBW and its association with maternal factors in India. They found tobacco exposure (both smoking and smokeless tobacco) was significantly associated with LBW baby (odd ratio 3.14). Rahman ME et al 15 conducted a casecontrol in Bangladesh to see the role of maternal tobacco use during pregnancy in the development of IUGR infants. A total of 75 cases and 150 controls were studied. Maternal smokeless tobacco use during pregnancy was associated $(71.9 \% \& 28.5 \%)$ with the development of IUGR infants $(\mathrm{p}<0.001)$ and carried a risk of having IUGR infants 6.4 times that non-tobacco users. A prospective cohort study

Prof. Dr Md. Ekhlasur Rahman, Professor and Head, Department of Pediatrics, Anwer Khan Modern Medical College

*Corresponding Author

AKMMC J 2018; 9(2) : 83-84 
done in Mumbai, India by Gupta PCet al ${ }^{16}$ showed that there was 1.6 times more risk of LBW for women who used ST than non-users.

Tobacco is a preventable cause of adverse pregnancy outcome. Intervention to quit tobacco includes behavior therapy and pharmacotherapy; the only drug readily available for quitting tobacco use is nicotine replacement therapy. Nic $\operatorname{VAX}^{17}$ is a nicotine conjugate vaccine intended to reduce or eliminate physical addiction to nicotine. Smoking \& Tobacco product usage Act should be followed up strictly, in that situation, rate of smoking can be curbed in Bangladesh.

\section{References}

1. Ravi S, Laurence S, Alen MF. Trends in Tobacco Use. Med Clin N Am 2004, 88(6): 1392.

2. World Health Organization. The Tobacco Atlas. Available from: http:/www.who.int/tobacco/ statistics/tobacco_atlas/en/ access on 01. 06 2018.

3. Global adult tobacco survey (GATS): Bangladesh. World Health Organization; 2009.

4. World Health Organization. Impact of Tobaccorelated Illness in Bangladesh. New Delhi; 2007.

5. Women and smoking. A report of Surgeon General. Executive Summary. MMWR Recomm Rep 2002; 51: I-iv, 1-13.

6. Andres RL, Day MC. Perinatal Complications Associated with Maternal Tobacco Use. Semin Neonatal 2000; 5: 231-41.

7. Centers for Disease Control and Prevention. 2007. Preventing Smoking and Exposure to Second hand Smoke Before, During and After Pregnancy Archived 11 September 2011 at the Wayback Machine.

8. Hackshaw, A. Rodeck C; Boniface S. "Maternal smoking in pregnancy and birth defects: a systematic review based on 173687 malformed cases and 11.7 million controls". Human Reproduction Update. 2011; 17: 589-604.
9. Muller JS, Antunes M, Behle I, Teixeira L, Zielinsky P. Acute Effects of Maternal Smoking on Fetal-Placental-Maternal System Hemodynamics. Arq Bras Cardiol 2002; 78: 152- 155.7.

10. Lambers D, Clark K. The Maternal and Fetal Physiologic Effects of Nicotine. Semin Perinatol 1996; 20: 115-126. 8.

11. Pastrakuljic A, Derewlany LO, Koren G. Maternal Cocaine Use and Cigarette Smoking in Pregnancy in Relation to Amino Acid Transport and Fetal Growth. Placenta 1999; 20: 499-512.

12. Slotkin TA. Fetal Nicotine or Cocaine Exposure: Which One is Worse? The Journal of Pharmacology and Experimental Therapeutics 1998; 285: 931-945.

13. Benowitz NL. Pharmacology of Smokeless Tobacco Use: Nicotine Addiction and Nicotinerelated Health Consequences. Nicotine Effect and Addiction. In National Cancer Institute, ST or Health: An International Perspective, Washington: US Department on Health and Human Services. Public Health Service: 1992; 93: 219-227.

14. Deshmukh JS, Motghare DD, Zodpey SP, et al. Low birth weight and associated maternal factors in an urban area. Indian Pediatrics 1998 Jan; 35:33-36.

15. Rahman ME, Khan IH, Parveen R. Role of Maternal Tobacco Use in The Development of IUGR infants. Sylhet Med J 2007; 30:16-22.

16. Gupta PC, Sreevidya S. Smokeless tobacco use, birth weight and gestational age: population based prospective cohort study of 1217 women in Mumbai, India. BMJ 2004 June 26; 328: 1538 .

17. NABI Biopharmaceuticals. Key Facts about Nic VAX and Nicotine Addiction. Available at: http/www.nabi.com. 